\title{
THE BIOLOGICAL ELEMENT IN HUMAN HISTORY*
}

BY

GEORGE ROSEN, M.D. Ph.D.†

THE study of man's structure and development revealed man's affinity with other animals and has given definite proof of his derivation from earlier forms of animal life. The human body is full of vestigial remains of earlier stages of man's life. Fundamentally, human history has depended upon physiological capacities and tendencies derived from animal ancestors, and it is therefore imperative for the historian to be aware of and to take into account these potentialities and inclinations. The development and growth of human civilization can undoubtedly be measured by the degree in which it has risen above the level of our animal ancestors and relatives. We know now that man is one of a vast number of living creatures and, like them all, is subject to a multitude of physical and biological factors. As far as our present knowledge goes, man stands revealed, in large part at least, as one of the many animals that inhabit the earth, in numerous ways both innocuous and obnoxious bound to his lowly relatives, and yet greatly superior to them by virtue of his much more highly developed mentality. Clearly, we cannot know ourselves nor can we know human history unless we realize our basic and uneradicable physically animal character.

Historians and other social scientists, recognizing that the biological character of the human organism manifested itself through certain physiological characteristics, needs and actions hastened to assume that one or the other of these was directly responsible for historical change. As a result, at one time or another efforts have been made to explain historical development in terms of the biological variation of the human species, that is, on the basis of race, in terms of population change, hunger, migration and disease. This propensity has both advanced and retarded our understanding of human history. One of Charles Beard's favourite quotations from Buckle was that 'the philosophy of any subject is not at its centre, but on the periphery where it impinges on all other sciences'. In this sense, biological theories of historical change owing to their monistic and overly simplistic character have tended in part to hide the complexity of historical process, but on the other hand by providing foci for criticism and analysis they have

* Based on a lecture delivered at Cooper Union, New York City.

$\uparrow$ School of Public Health and Administrative Medicine, Faculty of Medicine, Columbia University. 


\section{The Biological Element in Human History}

led to a deeper understanding of the role of such factors in the unfolding course of human history. This essay endeavours to consider the factors of race, population, hunger, migration and disease, and to show how the biological element in history is to be understood.

Recognizing the variety in the human species, some writers have asserted that race is the master key to an understanding of human history. In connection with this view, we may say at once that there are no longer any pure human races on this earth. And it seems quite clear that in the overwhelming majority of instances the behaviour of human groups is caused not by their racial inheritance, but rather by their cultural heritage. Hence, we cannot yet say definitely what the members of any so-called racial group owe to heredity and what they owe to experience in the collective sense. At best, from a formal, theoretical point of view, we may try to separate into categories what man owes to nature and what he owes to nurture.

In a very rough-and-ready way we may distinguish between certain inherited aptitudes and educational patterns and modes of behaviour that man acquires. Clearly, the historian must take into account racial origins if these are discoverable, but one of the most important things that we have learned so far, and this cannot be emphasized often enough, is that no matter what inherited differential characteristics may exist between allegedly distinct racial groups these are far less significant than differences in the social capacity of these groups.

A number of attempts have been made to use the racial explanation of human history, the most recent of which is certainly known to all of us, namely, the Nazi aberration. However, there have been other less crude forms of the same type of thinking that have exercised considerable influence on historical writing. For example, in the nineteenth century, Hippolyte Taine in his History of English Literature attempted to explain the activities of men by three elements in the human environment: race; milieu, or to use another phrase, social surroundings; and the Zeitgeist, or the spirit of the time. Taine, for instance, would have us believe that vice and virtue are as much products of these factors as any so-called material things. $\mathrm{He}$ would have us trace back the music of Protestantism until racial factors became involved. And race, he contended, is a product of the physical environment. Underlying this view is the profound influence of the great biological discoveries of the nineteenth century, in particular the Darwinian theory of evolution. According to Taine, much must be attributed to race. But what is race? Taine thought he knew: 'At every state of its existence', he said, 'a people remains one and the same, the five or six leading instincts which it obeyed in its native forests go with it into its palaces and administrative bureaus.' 


\section{George Rosen}

To say the very least, this is a highly dubious statement. As has already been pointed out, we know today that there are no pure races in the world, if indeed there ever were any. Nevertheless, it is still widely believed that difference of physical character implies a deep-rooted difference in mental and moral qualities, and that contrasting accomplishments of various people are due to differences of biological constitution. Consequently, it is thought that one race becomes a master because of its superior physique and mental capacity, while another succumbs owing to its inferiority in these qualities. As indicated in the quotation from Taine, this view naturally implies that a race preserves its character, not only in every region of the world where it may be situated, but also in every period of history. Thus the course of history is turned into a continued process of natural selection among races, some of which are retrogressive and others that are progressive. The former stagnate, the latter dominate.

A variant of the racial theory is that view which attributes the role in history of groups of human beings to their collective mentality and its constancy, or, in other words to race psychology. This standpoint, taken up by Wilhelm von Humboldt and developed by Steinthal and Lazarus, was extensively applied to history by Mommsen and Renan. Essentially, this type of explanation says that cultural developments and institutions are products of the genius of peoples. Thus Greek civilization was a creation of the inborn genius of the Greek race. This procedure is not illuminating for the definitions of collective mentality are not clearly defined and leave much room for debate, and then again the mode of operation of the postulated genius of the people is not indicated. It is clear that this is an example of the fallacy of misplaced concreteness, where one or more qualities, found together in a group of related phenomena, are abstracted, reified, and then used to explain events similar to those from which they were derived.

In the face of critical analysis, proponents of racial theories frequently tend to fall back on the influence of habitat or climate, and the racial explanation of history becomes in part at least a geographical one. It is argued that the history of different human groups has resulted from the effects of climate, soil, diet and inherited qualities, and no one will deny that there is an element of truth in this position. For example, the history of the Southern United States is related to climate, soil and health as much as to political factors. L. C. Gray in his History of Agriculture in the Southern United States to 1860 points out that dietary deficiencies, poor health and consequent low productivity have been important determinants of the history of this region. Hookworm-infested, undernourished, liquor-drinking, consumptive, malaria-ridden one-mule farmers explain, in part, the social retardation of the area; but at the same time closer scrutiny of the data 


\section{The Biological Element in Human History}

shows that these factors did not act directly, but rather affected and were effective through other, chiefly political channels.

In principle, it may be stated at this point that these theories as well as other biological explanations break down because nature does not enter directly into history. It does so by indirection. Or to put it differently: 'Pure' nature, physical and biological, which is presupposed to all human activity is actually effective in historical process as a nature mediated and modified through human social activity. Because of this, human history is not a process which is automatic and mechanical, but something which is capable of change and modification by our own present and future activity.

Population, like race, is one of the most publicized biological factors implicated in historical causation. To a very considerable degree this interest derives from the work of Malthus, which in a modified form still shapes public opinion. Even though the original Malthusian formulation implied that population change was a result rather than a cause, an inert rather than a dynamic factor in history, writers such as Benjamin Franklin and others took the view that the demographic situation can be a dynamic force in history rather than merely an inert one. Franklin pointed out that 'cities do not, by natural generation, supply themselves with inhabitants; their deaths are more than their births' (Writings, I907, III, 64), thus implying that increasing urbanization of an area would tend to restrict the growth of population in that area.

Historians have attempted to consider the decline of Rome as primarily a demographic phenomenon. However, the evidence of itself is hardly sufficient to justify such an interpretation. Somewhat clearer are the relations between economic crisis, demographic decline, and disease in fourteenth-century England. From the studies of Dobb, Russell and others it would seem that population declined after 1300 , probably due to declining productivity of labour on the peasants' lands. The immediate effect of this development was to threaten feudal society with a shrinkage of revenue and to produce an economic crisis. The destructive effect of the Black Death intensified the demographic decline and the economic crisis. These developments affected the landholders adversely and brought their interests into sharp conflict with those of the agricultural workers.

In general, the use of the population factor for explanatory purposes in historical analysis has been dominated by interest in a particular contemporary problem. In the nineteenth century this was a fear of overpopulation and population pressure, and even today, when the character of the problem in Europe and America has changed, this type of thinking may still have an historical influence, as witness the German cry for Lebensraum. Population affects history not only by increase but also by decline. In Western Europe, for example, the decline of fertility led governments to introduce various 


\section{George Rosen}

measures designed to affect the trend of fertility. Thus specific population policies have developed in Europe. Nevertheless, in all the instances that have been mentioned the effect of population on historical change seems to be that demographic change results from other, more deep-seated elements, and that demographic influence favours certain phases in a culture at the expense of others. The actual direction of the historical process is determined by other factors.

From time immemorial the course of human history is marked by widespread displacements of population. Among the causes of such displacements; war and famine take pre-eminent places. Driven abroad by the destruction of their homes in war, fleeing from the neighbourhood of battlefields or from the threat of enemy occupation, floods of refugees have always taken to the roads in search of a haven. Famines too have set large groups of people in motion. Numerous examples are scattered through history. In the fifth century A.D., for instance, hunger drove the German tribes to invade the fertile plains of Italy. Again in the Hungry 'Forties, the potato famine led thousands of Irish to migrate to the United States. In recent times we have had the Russian famine of $192 \mathrm{I}$, where hordes of people abandoned their homes and moved elsewhere to find food.

But as in the case of the other biological elements that have been mentioned, hunger and displacement exhibit their effects within an ongoing historical process. In Ireland, for instance, the great famine caused by the potato rot was but the climax of a process that had been in operation since the eighteenth century, namely, the siphoning off of the Irish peasant population as a result of economic distress.

Now let us consider theories that seek to explain historical change in terms of health and disease. In general, these follow the pattern of Simkhovitch's well-known paper on 'Hay and History' (Pol. Sci. Quart., $28: 385$, 1913), in which he sought to explain the decline of an empire through the depletion of soil and the consequent decline of population due to inability to produce food. In most of these theories, however, soil depletion is replaced by disease.

Disease is a biological process which is older than man. It is as old as life itself, and disease has had a considerable influence on the development of human history. The chief question in connection with the role of disease as a factor in human history is to determine whether it is of primary or secondary significance. Since disease has occurred at all times, all human institutions have been affected by it in one way or another, and man has had to reckon with it on several different levels.

Various theories have been put forth to explain the significance of disease in connection with human history. One of the more interesting of these explanations was offered in the middle of the last century by Rudolf 


\section{The Biological Element in Human History}

Virchow, the German founder of modern pathology. As an explanation of his views on the relations of medicine to society, Virchow developed a theory of epidemic disease as a manifestation of social and cultural maladjustment. Reasoning by analogy, he drew a parallel between the individual and the body politic: 'If disease is an expression of individual life under unfavourable conditions,' he pointed out, 'then epidemics must be indicative of major disturbances of mass life.' These disturbances are social and economic in character. For example: business depressions, unemployment, and the like. 'Don't we see that epidemics everywhere point to deficiences of society?' Virchow asked.

One may point to atmospheric conditions, general cosmic changes and the like, but in and of themselves these never cause epidemics. They always produce them only where, because of poor social circumstances, people have lived for a long time under abnormal conditions. Virchow differentiated natural and artificial epidemics, basing his distinction on the degree to which cultural factors interpose themselves between nature and man. Artificial epidemics, he pointed out, occur not only as a result of social contradictions, but also as significant manifestations of the historical process. Such outbreaks of disease occur at nodal points in history, during periods of political and intellectual revolution.

History has shown more than once (Virchow declared in August I848) how the fates of the greatest empires were decided by the health of their peoples or of their armies, and there is no longer any doubt that the history of epidemic diseases must form an inseparable part of the cultural history of mankind. Epidemics correspond to large signs of warning which tell the true statesmen that a disturbance has occurred in the development of his people which even a policy of unconcern can no longer overlook.

And a year later he carried this train of thought to its logical conclusion:

Epidemic diseases exhibiting a hitherto unknown character appear and disappear (he asserted) after new culture periods have begun, often without leaving any trace. As cases in point, take leprosy and the English Sweat. The history of artificial epidemics is therefore the history of disturbances which the culture of mankind has experienced. Its changes show us with powerful strokes the turning points at which culture moves off in new directions. Every true cultural revolution is followed by epidemics, because a large part of the people only gradually enter into the new cultural movement and begin to enjoy its blessings.

As the theory which endeavours to explain cycles of civilization in terms of malarial infection of a population is almost paradigmatic for biological explanations of historical change, the remainder of this paper will be devoted to a detailed analysis of this theory. In 1880, Alphonse Laveran discovered the malarial plasmodium, the protozoan organism which causes 


\section{George Rosen}

malaria by invading the blood-stream. In 1895, Ronald Ross found that the parasites were transmitted to man by the bite of anopheline mosquitoes. These classic discoveries went a long way towards explaining the mysteries of malaria and its spread. In the great excitement and enthusiasm created by the discoveries of Laveran and Ross, a theory was born which one might call the malarialistic explanation of history (the term has been borrowed from Erwin H. Ackerknecht).

In I 1909, W. H. S. Jones, one of the foremost students of Greek history, and a classical scholar, in collaboration with Ross, published an extremely challenging book entitled Malaria and Greek History. His thesis was that the Greeks who surrendered to the Roman legions were no longer the same as the Greeks who had repelled the Persian invaders, and that the change that had taken place in the interim was primarily due to the extension of malarial infection. Jones concluded that the decline of Greek power and culture during the fourth century B.c. was a result of the invasion of Greece by malaria a century earlier. Jones, of course, does not deny that other factors may have played a part, but it is his contention that a strong healthy people reacts against such factors and overcomes them. Malaria, however, saps the vital nature of a people, destroys their stamina and leads to their degeneration.

Similar views were put forth by Angelo Celli, one of the outstanding epidemiologists of malaria, who had spent a considerable part of his life in efforts to control the disease in Italy. Celli made an extensive study of the history of the Roman Campagna. And he was struck by the fact that this region had at times been a complete desert and at other times had been a flourishing landscape teeming with life. Celli found that in the course of twenty-five centuries the history of the Campagna could be divided into four periods: (I) the pre-Roman period; (2) the period when Imperial Rome was at the height of its power; (3) during the early Middle Ages, that is, the eighth and ninth centuries; and (4) in modern times from the fifteenth to the seventeenth centuries. During these periods the Campagna had been inhabited and had flourished mightily, while between these periods it had been a place of desolation, uninhabited by man and frequented only by wild animals. And so Celli raised the question: What was the explanation of this interesting phenomenon? In answer, Celli made malaria responsible for the vicissitudes of the Campagna. In the course of extended historical studies, he showed that in certain regions malaria occurs in periodic cycles. The disease invades a region, overwhelms it, and drives out all human life. And then centuries later, for reasons still not completely established, the disease gradually peters out. It recedes and human activity again returns to the scene.

There is no doubt that malaria was a factor in the historical 'ups and I 56 


\section{The Biological Element in Human History}

downs' of the Roman Campagna. As Celli expressed it, 'Wherever malaria is dominant the history of malaria is in a certain sense the history of the nations.' This malarialistic theory of history was also applied to other civilizations that had flourished and disappeared mysteriously; for example, the culture that had existed on Ceylon from about I 50 B.C. to about A.D. IOo.

In reviewing the evidence both for and against this view which makes a disease a primary factor in human history, one cannot help but feel that this interpretation is, in a manner of speaking, a way of looking at things upside down, a point of view which stands things on their head. To return to the case of Greek civilization-here was a culture limited economically by its foundation (slavery), politically limited by its inability to transcend the city-state (the polis), morally disintegrated by the loss of its original religious faith, a faith which had been in a sense the only existing common ideological denominator among the Greeks-it would seem that this civilization was doomed with or without malaria, and all that malaria could do or did do was to accelerate, in the role of a secondary factor, a process of disintegration that was already under way, and to hinder in one way or another attempts at recovery and reconstruction. It would appear that a Greece still motivated by its original dynamic would have conquered malaria just as medieval Europe, in many ways, quickly healed the wounds inflicted by the Black Death. To take the present as a case in point-after all, we see the historic culture of Europe going to pieces before our very eyes as did ancient Greece for similar reasons, and we see that European civilization has no need of malaria or any other disease to accomplish its self-destruction.

Or to take up the evidence adduced by Celli. Why should we regard the 'ups and downs' in the history of the Roman Campagna as the expression of some mysterious mystical periodicity of malaria subject to no other laws of history, and itself subjecting historical development to its own law? May we not see here a reflection of certain idealistic philosophies of history, much as that of Hegel with his explanation of history as the unfolding of Absolute Mind?

Actually, when the evidence brought forth by these authors is considered as objectively as possible, we always see that it is devastation by war, or social and economic pressures which force the inhabitants, in particular the peasants, to abandon the land. This in turn almost automatically leads to an increase of the anopheline population, and in turn this leads to an increase of the disease. On the other hand, it is also evident that it was during its periods of greatest power and wealth that Rome was able to overcome the evil spell cast upon it by malaria. Would it not then be less artificial to account for the waves described by Celli in terms of the latter facts rather than vice versa? 


\section{George Rosen}

Of course, it would be entirely foolish to deny to malaria any influence on history, nor is there any desire to do so. The problem under discussion, however, is rather whether or not malaria is a primary factor in history; and in this respect it is my view that malaria everywhere seems to be manmade, to be caused by history-that is, by the complex social, economic and ideological factors that go to make up history-rather than to cause history. That malaria, once having entered a weakened social organism, creates a vicious circle and forms an enormous obstacle to the recovery or growth of such a society is indeed obvious. Yet, on the other hand, only a very cursory examination of history shows that victory over malaria is possible as long as the fundamentally sound character of the society exists and as long as its response to this challenge is dynamic. In illustration of this, let us take only two well-known examples.

For the first, let us consider the extensive malarialization of such European countries as England, France, Holland and Germany during the sixteenth, seventeenth and eighteenth centuries. Despite the extensive existence of the disease, the rise and development of their civilization could neither be broken nor prevented. And for the second, if we consider the American Middle West, which was most heavily infected with malaria during the nineteenth century, we find that it neither collapsed nor stopped in its evolution.

It is quite clear that in a given locality malaria may be efficient in making people abandon one site and choose another healthier spot. Malaria may exert very subtle influences; it may have helped the white man in his conquest of native populations: for example, the American Indian and the Polynesian. But even taking all these phenomena into account, they do not entitle us at the present state of our knowledge to credit malaria with the role of a primary factor in the historical process.

In summing up the case of malaria one can say that historical events have brought about the malarialization and de-malarialization of countries; and that malaria, on its side, has contributed to the shaping of historical events. The varied record of malaria in the past leads us to speculate that its future development also will not be as uniform as some have assumed on the basis of purely biological reasoning.

Brief mention should also be made of another aspect of this subject-the effect of disease on war. Hans Zinsser in his interesting and clever book, Rats, Lice and History, has a chapter entitled 'On the Influence of Epidemic Diseases on Political and Military History, and On the Relative Unimportance of Generals'. The point which he makes is well taken, for throughout history there are enough examples of military plans that have failed because the possibility of disease was not considered. Here, again, disease is one factor in a constellation of factors, and any attempt to single it out and make it alone responsible is doomed to failure. 


\section{The Biological Element in Human History}

Finally, there is the question whether the illnesses of persons in positions of power may not exert crucial effects on historical development. In part this question is related to the problem of great men in history. In his novel, War and Peace, for example, Tolstoy discusses this problem in relation to the claim of certain historians that the French lost the Battle of Borodino on 7 September 1812 , because Napoleon had a cold. Tolstoy ridicules this naive conception of historical causality, pointing out that if this view is correct, then the attendant who forgot to give Napoleon his watertight boots is really the person who changed the course of history and saved Russia. He makes the point that disease or death of an important individual does not alter the course of history. To be sure, history is made by individuals, and it makes a difference whether they are healthy or sick, but the fact remains that the actions of individuals are determined by a multitude of factors, social, economic, biological and psychological, and not alone by some physical ailment. In fact, there are enough historical examples to show that causes can outlive leaders: for example, the influence of the Rooseveltian New Deal on recent American politics.

In conclusion, the role of the biologic element in history may be summed up as follows: Man is a biological organism in a natural world containing various physical and biological elements. But man is also a social organism capable of creating a social environment which he interposes between himself and nature. For this reason historical phenomena cannot be derived directly from any kind of extra-social natural factors such as race, climate, or struggle for existence, but rather from a nature which has itself already been modified by socio-historical process. There is no doubt that biological factors such as race, population or disease play a role in human history, but the effect produced is mediated through human activity. Thus, human disease is not a purely biological but rather a socio-biological phenomenon and must be treated as such. The task of the historian is to seek out and to analyse where, when and how human culture and biology have interacted and affected each other. 